\title{
Conditioned analgesia in the rat
}

\author{
A. JOHN MacLENNAN, RAYMOND L. JACKSON, AND STEVEN F. MAIER \\ University of Colorado, Boulder, Colorado 80309
}

\begin{abstract}
It has been suggested by recent studies that the analgesic reaction to electric shock can be conditioned. However, these studies either lacked shocked controls or used an indirect measure of analgesia (freezing). In the present investigation, each rat was exposed an equal number of times to two distinct environmental contexts. The rats were shocked in one context and reexposed to the same context before test, shocked in one context and reexposed to the nonshock context before test, or not shocked at all and reexposed to one of the two contexts. Immediately following reexposure, the pain reactivity of the rats was assessed by a hot plate (Experiment 1) and a tail-flick apparatus (Experiment 2). It was found that rats that were reexposed to the context in which they had been shocked were significantly more analgesic than rats in the other two groups (which did not differ). These results confirm that it is possible to condition shock-induced analgesia in the rat.
\end{abstract}

A variety of recent research has focused on psychologically produced alterations in the organism's perception of and reactivity to painful stimuli (see review by Liebeskind \& Paul, 1977), as well as the role of such alterations in the production of a variety of behavioral phenomena (cf. Fanselow, 1979; Jackson, Maier, \& Coon, 1979). Particularly interesting in this regard are reports that exposure to a variety of stressors produces an analgesic reaction that persists for up to $2 \mathrm{~h}$ (Akil, Madden, Patrick, \& Barchas, 1976; Amir \& Amit, 1978; Bodnar, Kelly, \& Glusman, 1978; Hayes, Bennett, Newlon, \& Mayer, 1978). The potential implications of these stress-induced analgesic reactions for behavioral and pharmacological phenomena have been increased by three recent experiments designed to demonstrate that the analgesia can be classically conditioned to cues that precede or accompany the aversive event. The first was reported by Chance, White, Krynock, and Rosecrans (1977). Rats were shocked in a distinctive context and then given a tail-flick test in that context. Unfortunately, the only control group used was one in which no shock at all was delivered. Thus it is possible that the decreased responsiveness to radiant heat on the tail-flick test represents an unconditioned effect of shock rather than a classically conditioned antinociceptive response. In a second experiment, Chance, Krynock, and Rosecrans (1978) employed a control procedure in which the subjects were exposed to shock. However, the handling, shock delivery, and stimulus conditions differed between the experimental and controls, and so the attribution of the analgesic response to conditioning can again not be made with certainty.

This research was supported by NSF Grant BNS 78-00508 to Steven F. Maier. Raymond L. Jackson is now at the University of Texas at Arlington, Arlington, Texas. Requests for reprints should be sent to A. John MacLennan, Department of Psychology, University of Colorado, Boulder, Colorado 80309.
Recognizing these difficulties, Fanselow and Bolles (1979) provided a more usual control procedure. Experimental subjects received forward pairings of a tone and shock, and the controls received backward pairings. In order to test whether an analgesic response had become conditioned to the tone CS, the tone CS was later presented in a different chamber and was followed by a shock. The behavior measured was postshock freezing. Fanselow and Bolles argued that the amount of postshock freezing is a measure of pain reactivity. The basis for this argument is that the amount of postshock freezing is a direct function of shock intensity and is attenuated if naloxone, an opiate antagonist, is administered before the shocks (Fanselow \& Bolles, 1979). The results were that postshock freezing was smaller in magnitude in the forward conditioning group than in the backward group and that this difference was eliminated by treatment with naloxone.

Although the Fanselow and Bolles (1979) study employed an appropriate control group, it added a potential difficulty of its own. Postshock freezing is not a widely used measure of pain sensitivity or reactivity, and only Fanselow and Bolles seem to have used it for this purpose. The fact that there is a direct relationship between shock intensity and postshock freezing is suggestive, but it could be interpreted in a number of ways. In fact, Fanselow and Bolles note that data from both Blanchard and Blanchard (1969) and Bolles and Collier (1976) suggest that postshock freezing is a response to the fear-arousing properties of contextual cues that have been associated with shock. Obviously, this, too, would produce a direct relation between freezing and shock intensity. Such a possibility raises a special problem here, because "blocking" (OddlingSmee, 1978) should produce less conditioning to contextual cues during testing in the forward conditioning than in the backward conditioning group (cf. Dweck \& Wagner, 1970). Thus, the Fanselow and Bolles results could reflect differences in contextual conditioning 
during testing produced by differential blocking rather than differential pain.

The elimination of the postshock freezing difference by naloxone is again suggestive but not conclusive. It is not decisive because naloxone affects many processes other than pain reactivity (see Sawynok, Pinsky, \& LaBella, 1979, for a review), and many of these could interact with postshock freezing.

Because the conditioning of stress-induced analgesic reactions is a phenomenon of some potential significance, we report two experiments that attempt to combine the use of procedures that equalize the treatment between experimental and control subjects with standard testing procedures used in the assessment of pain sensitivity. We should note that these experiments were not undertaken because we believed the results of Chance and his colleagues (Chance et al., 1978; Chance et al., 1977) and Fanselow and Bolles (1979) to be in error. They were initiated independently, and we report them only because we believe the phenomenon involved to be an important one.

\section{EXPERIMENT 1}

The general design was one in which animals repeatedly received inescapable shocks in one environment but not in a different environment. The animals were then exposed to one environment or the other, and then they were immediately given a standard hot-plate painsensitivity test. Control subjects were restrained in the various environments, but they were not shocked.

\section{Method}

Subjects. Forty albino rats obtained from the Holtzman Company of Madison, Wisconsin, served. The animals were 80-90 days old at the start of the experiment. They were maintained on a 12-h light-dark cycle and had food and water continuously available in their home cages.

Apparatus. Shock and restraint occurred in tubes and wheelturn boxes. The tubes were made of Plexiglas and were $23.4 \mathrm{~cm}$ in length and $7.0 \mathrm{~cm}$ in diameter. The rat's tail extended from the rear of the tube and was taped to a Plexiglas rod. Unscrambled shocks were delivered to the tail via fixed electrodes from a shock source modeled after the Grason-Stadler Model 700. The tubes were housed in a dimly illuminated room.

The wheel-turn boxes were $15.5 \times 12.0 \times 17.0 \mathrm{~cm}$. The side and front walls were made of Plexiglas; the rear wall and floors were made of masonite. A grooved Plexiglas wheel extended $1.7 \mathrm{~cm}$ in to the chamber. Shock delivery was as in the restraining tubes. The wheel-turn boxes were housed in a brightly illuminated room.

Analgesia testing was conducted using a hot plate. It consisted of a $27.5 \times 43 \mathrm{~cm}$ copper plate placed on top of a constanttemperature water bath. Plexiglas walls enclosed the plate and prevented the subjects from leaving the plate. The surface was maintained at $48.5^{\circ} \mathrm{C} \pm .5^{\circ} \mathrm{C}$.

Procedure. The rats were randomly divided into four groups of 10 . Each rat spent three 1.5 -h sessions restrained in a wheelturn box and three 1.5-h sessions restrained in a restraining tube, with one session occurring on each of the first 6 days of the experiment. A counterbalanced pseudorandom schedule determined where the rats spent their sessions each day. Rats in one experimental group (wheel-shock) received $80 \quad 5$-sec 1 -mA inescapable shocks during each session they spent in a wheel-turn box. They were not shocked during their sessions in the restrain-
Table 1

Mean Paw-Lick Latencies (in Seconds) of Experimental and Control Subjects Tested After Exposure to One of the Two Environments

\begin{tabular}{ccccc}
\hline \multicolumn{2}{c}{ Experimental } & & \multicolumn{2}{c}{ Control } \\
\cline { 5 - 5 } Shocked & Nonshocked & & Shocked & Nonshocked \\
\hline 20.44 & 10.73 & 12.31 & 13.18 \\
\hline
\end{tabular}

ing tube. Rats in another experimental group (tube-shock) were identically shocked during each session spent in a restraining tube. They did not receive shock when in the wheel-turn boxes. Therefore, the only difference in the treatment of the two experimental groups was the apparatus in which they were shocked. On Day 7, half of the rats in the wheel-shock and tubeshock groups were placed in the apparatus in which they had not been shocked. The rats in the two nonshocked control groups (wheel-nonshock and tube-nonshock) were likewise divided and assigned to particular apparatuses as if they had been shocked in the same apparatus as their respective experimental groups. Five minutes after being placed in an apparatus, each rat was removed and placed on the hot plate $\left(48.5^{\circ} \mathrm{C} \pm .5^{\circ} \mathrm{C}\right)$ until it licked a hind paw. Paw-licking latencies were recorded by an observer unaware of group membership.

\section{Results and Discussion}

There were no differences between animals shocked in the restraining tube and the wheel-turn box. Thus the data from these groups were combined. Two subjects were discarded due to procedural error. Table 1 shows the mean paw-lick latencies for animals that had been shocked during training and placed in the apparatus in which they had been shocked before testing (experimental/shocked apparatus), animals that had been shocked and tested after placement in the nonshocked apparatus (experimental/nonshocked apparatus), and animals that had not been shocked and tested after placement in one of the two apparatuses (control/ shocked apparatus, control/nonshocked apparatus). The results are quite clear. Rats that had been shocked during training and placed in their shocked environment became analgesic; rats that had been shocked but were tested after placement in their nonshocked environment did not. This conclusion was confirmed by a 2 by 2 analysis of variance. The effects of testing apparatus $[F(1,34)=6.37, p<.05]$ and the interaction between testing apparatus and shocking during training $[\mathrm{F}(1,34)=$ $9.06, \mathrm{p}<.01]$ were reliable. The main effect of shock during training was not reliable $[F(1,34)=2.65]$. A subsequent Newman-Keuls test $(p<.05)$ revealed that the shocked group tested after exposure to their shocked apparatus differed from the other three groups, which did not differ among themselves.

\section{EXPERIMENT 2}

The results of Experiment 1 indicate that an analgesic reaction can be conditioned to cues that accompany the presentation of shock. The purpose of Experiment 2 was to confirm this result using a different measure of pain reactivity and different environmental cues. Thus, Experiment 2 followed the same design as did Experi- 
Table 2

Mean Tail-Flick Latencies (in Seconds) of Experimental and Control Subjects

\begin{tabular}{ccc}
\hline \multicolumn{2}{c}{ Experimental } & \\
\cline { 2 - 3 } Shocked & Nonshocked & Control \\
\hline 12.14 & 9.14 & 9.46 \\
\hline
\end{tabular}

ment 1 but employed a tail-flick test as the measure of pain sensitivity. Here, radiant heat is focused on the tail, and the latency to deflect the tail is measured.

\section{Method}

Subjects. The subjects were 36 rats of the same sex, age, and supplier as in Experiment 1.

Apparatus. The same restraining tubes and wheel-turn boxes were used as in Experiment 1. However, opposite to Experiment 1 , the room housing the wheel-turn boxes was dimly lit, whereas the room housing the restraining tubes was brightly lit. In addition, $60-\mathrm{dB}$ white noise was present in the restraining tube room, and a drop of vanilla extract was put in each wheelturn box before each rat. The tail-flick test device consisted of a $43.0 \times 17.7 \times 8.0 \mathrm{~cm}$ (length by width by height) metal box that supported a $7.4 \times 3.0 \mathrm{~cm}$ (length by width) aluminum plate. A shallow groove was cut in this plate, and the rat's tail was put in this slot during a trial. A photocell receiver was located in this groove. A General Electric 150-W projector spotlight was mounted above the plate that held the rat's tail. The distance between the lamp and the tail was adjustable. A condenser lens was located between the light source and the tail and served to focus the light. The position of the lens was fixed, and its flat surface was located $6.5 \mathrm{~cm}$ above the aluminum plate. A 5- to 7-mm deflection activated the photocell and automatically terminated the trial.

Procedure. The procedure was as for Experiment 1. It differed only in that a tail-flick test replaced the hot-plate test. Here, an experimenter (unaware of group membership) held the rat and placed its tail in the grooved metal plate. A switch actuated the lamp and started a timer. The light beam was focused on a spot halfway between the tip and the base of the tail. A trial was automatically terminated if a tail flick had not occurred within $20 \mathrm{sec}$.

\section{Results and Discussion}

Table 2 presents mean tail-flick latencies for shocked subjects tested after exposure to the environment in which they had been shocked (experimental/shocked apparatus), for shocked subjects tested after placement in their nonshocked environment (experimental/nonshocked apparatus), and for the nonshocked subjects (controls). Again, the previously shocked subjects responded slowly when tested after exposure to the environment in which they had been shocked but did not respond slowly when tested after placement in the apparatus in which they had not received shock. A one-way analysis of variance revealed a reliable effect of groups $[F(2,33)=3.89, p<.05]$. A subsequent Newman-Keuls test $(p<.05)$ found the shocked group tested after exposure to their shocked environment to differ from the remaining two, which did not differ from each other.

\section{GENERAL DISCUSSION}

The results of these two experiments confirm those of Chance and his colleagues (Chance et al., 1978; Chance et al., 1977) and Fanselow and Bolles (1979). We employed two standard tests of pain reactivity and a control procedure that insured that any analgesic response that might occur could not be attributed to exposure to shock per se or differential handling, shock delivery, or stimulus factors, and we still found evidence for a conditioned antinociceptive reaction. The shocked subjects were exposed to two sets of contextual cues during training, but they only displayed an analgesic reaction if the contextual cues were presented with the set that had been present during shock delivery.

The fact that analgesic reactions became conditioned to cues that precede aversive stimulation is important for a number of reasons. First, such conditioned analgesic reactions might be involved in the mediation of a large number of behavioral phenomena heretofore attributed to other factors. For example, Fanselow (1979) has argued that organisms may prefer signaled to unsignaled shock because the signal comes to elicit an analgesic reaction and thus decreases the painfulness of shock. Other phenomena in which conditioned analgesia may play some role are US preexposure effects, blocking, and the learned helplessness effect. This is not to suggest that any of these phenomena are entirely attributable to conditioned analgesic reactions, but only that such reactions may be involved.

Conditioned analgesia is also of interest because it suggests that the activity of the system(s) that produces the analgesic reaction in response to stress can be brought under the control of neutral environmental stimuli. Particularly interesting in this regard are the opioid peptides. These substances appear to be released in response to stress (Madden, Akil, Patrick, \& Barchas, 1977) and are capable of producing decreased pain responsivity (see Liebiskind \& Paul, 1977; Terenius, 1978, for reviews). It is a matter of dispute whether the opioid peptides are responsible for stress-induced analgesia (see Bodnar, Kelly, Steiner, \& Glusman, 1978), but their potential conditionability is of some interest.

\section{REFERENCES}

Akil, H., Madden, J., Patrick, R. L., \& Barchas, J. D. Stress-induced increase in endogenous opiate peptides: Concurrent analgesia and its partial reversal by naloxone. In $\mathrm{H}$. Kosterlitz (Ed.), Opiates and endogenous opiate peptides. Amsterdam: Elsevier/North Holland Biomedical Press, 1976.

Амır, S., \& Амıт, Z. Endogenous opioid ligands may mediate stress-induced changes in the effective properties of pain related behavior in rats. Life Sciences, 1978, 23, 1143-1152.

Blanchard, R. J., \& Blanchard, D. C. Crouching as an index of fear. Journal of Comparative and Physiological Psychology, $1969,69,370-375$.

Bodnar, R. J., Kelly, D. D., \& Glusman, M. Stress-induced analgesia: Time course of pain reflex alterations following cold water swims. Bulletin of the Psychonomic Society, 1978, 11, 333-336.

Bodnar, R. J., Kelly, D. D., Steiner, S., \& Glusman, M. Stress-produced analgesia and morphine-produced analgesia: Lack of cross-tolerance. Pharmacology, Biochemistry and Behavior, 1978, 8, 661-666.

Bolles, R. C., \& Collier, A. C. The effect of predictive cues on freezing in rats. Animal Learning \& Behavior, 1976, 4, 6-8.

Chance, W. T., Krynock, G. M., \& Rosecrans, J. A. Antinociception following lesion-induced hyperemotionality and conditioned fear. Pain, 1978, 4, 243-252.

Chance, W. T., White, A. C., Krynock, G. M., \& Rosecrans, J. A. Autoanalgesia: Behaviorally activated antinociception. European Journal of Pharmacology, 1977, 44, 283-284. 
DWeck, C. S., \& W Agner, A. R. Situational cues and correlation between CS and US as determinants of the conditioned emotional response. Psychonomic Science, 1970, 18, 145-147.

FANSELow, M. S. Naloxone attenuates rat's preference for signaled shock. Physiological Psychology, 1979, 7, 70-74.

Fanselow, M. S., \& Bolles, R. C. Triggering of the endorphin analgesic reaction by a cue previously associated with shock: Reversal by naloxone. Bulletin of the Psychonomic Society, 1979, 14, 88-90.

Hayes, R. L., Bennett, G. J., Newlon, P. G., \& Mayer, D. J. Behavioral and physiological studies of non-narcotic analgesia in the rat elicited by certain environmental stimuli. Brain Research, 1978, 155, 69-90.

JACKSON, R. L., MAIER, S. F., \& Coon, D. J. Long-term analgesic effects of inescapable shock and learned helplessness. Science, 1979, 206, 91-93.
Liebeskind, J. C., \& Paul, L. A. Psychological and physiological mechanisms of pain. Annual Reviews of Psychology, 1977, 28, 41-60.

Madden, J., IV, Akil, H., Patrick, R. L., \& Barchas, J. D. Stress-induced parallel changes in central opioid levels and pain responsiveness in the rat. Nature, 1977, 265, 358-360.

ODdLing-SmeE, F. J. The overshadowing of background stimuli by an informative CS in aversive Pavlovian conditioning with rats. Animal Learning \& Behavior, 1978, 6, 43-52.

Sawynok, J., Pinsky, C., \& LaBella, F. S. On the specificity of naloxone as an opiate antagonist. Life Sciences, 1979, 25, 1621-1632.

Terenius, L. Endogenous peptides and analgesia. Annual Reviews of Pharmacology and Toxicology, 1978, 18, 189-204.

(Received for publication April 15, 1980.) 